Institutional Structure of Health Care in Rural Cameroun:

Structural Estimation of Production in Teams with

\title{
Unobservable Effort
}

by

Kenneth L. Leonard, Columbia University

July 1998

Discussion Paper Series No. 9798-16

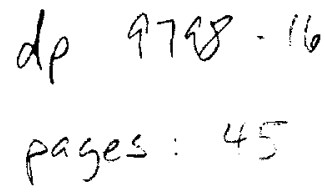




\title{
Institutional Structure of Health Care in Rural Cameroun: Structural Estimation of Production in Teams with Unobservable Effort
}

\author{
Kenneth L. Leonard* \\ Department of Economics \\ Columbia University
}

July, 1998

\begin{abstract}
Traditional healers in Cameroun are paid on an outcome-contingent basis, where payments are linked to the recovery of the patient. On the other hand, organizational providers (government clinics and hospitals and church-based clinics and hospitals) are paid a fixed fee at the time of consultation. Is this 'custom' of payment method at the traditional healer a response to a problem of imperfect information in the supply of medical care? Eswaran and Kotwal (1985) suggest that share-cropping is a response to imperfect information in the supply of factor inputs owned by land-lords and tenants. Because different crops require different levels of inputs, one form of contract might be particularly appropriate for some crops but not others. We suggest that contingentpayment contracts are appropriate for some health production technologies and that fixed fee contracts are appropriate for other technologies, where a technology in health care is the medical response indicated by a set of presenting conditions.

We fit a contractual model of health care demand to data on observed patterns of provider and contract choice using a Conditional Logit. Effort exerted on behalf of the patient's health is unobservable and is therefore only delivered according to the incentives that exist within the implicit contract between patient and provider. Patients create an approximate market for medical effort by choosing between discrete contract types.

Institutions and organizations play an essential role in the creation of credible quality. With simulation we show that the government can greatly reduce transaction costs (and increase net utility) by specifically recognizing its role as an organization within the context of the institution of modern health care.
\end{abstract}

JEL Classification: D8 I1 O2

Keywords: Traditional Healers, Institutions, Rural Health Care, Contracts, Imperfect Information, Unobservable Effort, Production in Teams

*This work was funded by NSF grant number 94-22768 and a University of California Rocca Fellowship. 


\section{Introduction}

Traditional healers in Cameroun are paid on an outcome-contingent basis, where payments are linked to the recovery of the patient. On the other hand, organizational providers (government clinics and hospitals and church-based clinics and hospitals) are paid a fixed fee at the time of consultation. Is this 'custom' of payment method at the traditional healer a response to a problem of imperfect information in the supply of medical care? Eswaran and Kotwal (1985) suggest that share-cropping is a response to imperfect information in the supply of factor inputs owned by land-lords and tenants. Because different crops require different levels of inputs, one form of contract might be particularly appropriate for some crops but not others. We suggest that contingent-payment contracts are appropriate for some health production technologies and that fixed fee contracts are appropriate for other technologies, where a technology in health care is the medical response indicated by a set of presenting conditions.

There are distinct patterns in the types of diseases that are reported at traditional and organizational providers (Leonard 1998). Diseases reported at traditional healers are characterized by high returns to medical and patient effort. We fit a contractual model of health care demand to data on observed patterns of provider and contract choice from the South West Province of Cameroun. Effort exerted on behalf of the patient's health is unobservable and is therefore only delivered according to the incentives that exist within the implicit contract between patient and provider. Patients create an approximate market for medical effort by choosing between discrete contract types.

We extend the Grossman (1975) model of investment in health capital by assuming imperfect factor markets as developed in Eswaran and Kotwal (1985). Both provider and patient play a bilateral-effort principal-agent game as in Holmstrom (1982). With this relatively simple specification of incentives we show that, because diseases require a different mix of patient and medical inputs in their treatment, different types of contracts are better for different diseases.

This paper focuses on patients' choices between the five most commonly visited types of providers. The government of Cameroun runs clinics and hospitals. In addition there are 
a variety of clinics and hospitals run by churches. Both government and mission hospitals are similarly staffed and equipped, and both types of clinics are similarly staffed and equipped. All government centers are similarly managed and mission centers are similarly managed. Hospitals and clinics differ according to skill and government and mission facilities differ according to management. The fifth choice are traditional healers who remain popular among all ages and classes of rural Cameroun. We interviewed traditional healers ${ }^{1}$ and examined secondary sources for information about the practice of traditional rnedicine $^{2}$. Traditional healers have very different incentives than other providers because they accept payment for services contingent on a successful outcome, whereas the other four providers only accept fixed payments. Incentives to provide effort at clinics and hospitals come in the form of penalties from employers when standards for care are not met. Mission centers have the potential to impose significantly higher penalties than do their government counterparts. Each provider offers a different mix of skill and incentives to provide effort.

We follow the convention of North (1990) and use the term institutions to refer to rules or conventions of interaction between players. Organizations, on the other hand, "are groups of individuals bound by some common purpose" and are seen as players within the context of institutions. The provision of health care is governed by two very different institutions, within which our five providers operate. Thus we view mission and government health services as organizations that operate within the institution of modern medicine and traditional healers as individuals who operate within the institution of traditional medicine.

Our data include the characteristics of the disease or conditions ${ }^{3}$ from which patients

\footnotetext{
${ }^{1}$ By traditional healers we mean rural health practitioners who run practices that resemble health practices that existed before the spread of 'western' medicine into the rural areas. We do not imply that all traditional healers use herbal medicines, nor that no non-traditional practitioners use herbal medicines. Our distinction is by method of practice not by types of medicines used.

${ }^{2}$ For details of the interviews see Leonard (1998). Secondary sources were Korse et al. (1989), Baerts (1989), Edwards (1983), Oyenye and Orubuloye (1985), Lasker (1981), Staugărd (1985), Gelfand, Mari, Drummond and Ndemera (1985) and Conco (1972).

${ }^{3}$ All illness episodes are characterized as a series of symptoms and complaints, however for simplicity's sake we will often refer to these as diseases, even though we can never be sure from what disease a person was suffering.
} 
suffered as well as characteristics of the patient and the expected costs at each practitioner. By assuming that choices are made based on expected net utility we use a conditional logit structural estimation to recover the parameters of the production-of-health-investment function as well as the parameters of the contracts between patients and providers for the delivery of medical and patient effort. The results of our estimation illustrate how the characteristics of disease affect the choice of contract, how the characteristics of the patient affect her ability to transform health care into health, and how the opportunity cost of healthy time affects the relative weight of costs and incentives in the choice of health care provider. We conclude that patients choose a provider because the contract under which medical effort is delivered is appropriate to the condition from which the patient suffers.

The contractual estimation allows us to investigate some potential government policies. We find that policies that directly address the transaction costs created by asymmetric information are the policies that create the greatest increase in utility for the population at the lowest cost to the government.

This paper is organized as follows. In section 2 we outline our model of health production. We develop an explicit characterization of the contract available at each provider and the levels of effort that the patient can expect at each provider. In Section 3 we discuss the data that we collected in Cameroun. A structural estimation is presented and the results are discussed in Section 4. In Section 5 we present the results of policy simulations. Section 6 concludes.

\section{Health care as a production good}

Patients balance the cost of visiting a particular practitioner against the expected benefit of health care. We follow Grossman (1975) and model the benefit of health care as an increase in health stock. Health stock determines time available for work and leisure. This stock depreciates over time, can be increased by investment in health care and is subject to negative shocks from illness. In our model individuals purchase health care because they have received a negative shock to their health stock that creates a demand for investment 
in health.

$X$ is the outcome of investment in health care; the change in the number of healthy hours. The unconditional probability of $X$ is given by its distribution function $\Phi\left(X ; \mu, \sigma_{k}\right)$, and is an increasing function of $\mu . \mu$ is a function of the effort of the practitioner, $a$, the effort of the patient, $b$, characteristics of the disease $\psi_{k}$, characteristics of the practitioner $\psi_{j}$, and characteristics of the patient $\psi_{i}$ where $\mathrm{k}$ is the disease index, $\mathrm{j}$ the practitioner index and $\mathrm{i}$ the individual index; $\mu=f\left(a, b, \psi_{k}, \psi_{j}, \psi_{i}\right)$. The standard error $\sigma_{k}$ of $X$ is a function of the disease characteristics only.

Payments to health care practitioners differ across providers but can involve fixed fees (paid before a consultation), an outcome-contingent fee (paid after the outcome is observed) and drug costs. Traditional healers charge a fixed fee and negotiate with the patient over a schedule of further payments before the treatment begins. Traditional healers do not charge for drugs. Government and church-operated clinics and hospitals charge a fixed fee for consultation and charge for all drugs administered.

We simplify the contingent payment to the traditional healer as a share of the value of the outcome, thus $r_{j k} \omega_{i} X$, where $\omega_{i}$ is the opportunity cost of healthy time and $r_{j k}$ is a fixed share such that $0 \leq r_{j k} \leq 1$. Drug costs for traditional healers are 0 and $r_{j k}=0$ for all providers except the traditional healer.

Income for patient $i$, treated at provider $j$ for illness condition $k$ is

$$
Y_{j}^{p}=\left(1-r_{j k}\right) \omega_{i} X-\left(f c_{j}+d c_{j k}+t c_{i j}\right)
$$

where $f c_{j}$ are fixed fees, $d c_{j k}$ are drug costs and $t c_{i j}$ is the travel cost. The travel cost is a function of the individual (origin) and the practitioner visited (destination), the drug cost is a function of the practitioner and the disease, and the fixed cost is a function only of the practitioner. The income of the practitioner is the sum of all payments by the patient, not including travel costs.

$$
Y_{j}^{m}=r_{j k} \omega_{i} X+d c_{j k}+f c_{j}
$$


The patient is risk neutral and has utility only over expected income and disutility of effort, where the mean of the outcome is $\mu$, and $d(b)$ is the disutility of effort.

$$
E\left(U^{p}\right)=\underbrace{\left(1-r_{j k}\right) \omega_{i} \mu(a, b, \psi)}_{\text {retained earning increase }}-\underbrace{d(b)}_{\text {disutility }}-\underbrace{\left(f c_{j}+d c_{j k}+t c_{i j}\right)}_{\text {costs }}
$$

\subsection{Unobservable inputs}

The demand for health investment depends on the price of the factor inputs. However, we claim that there are imperfect markets for patient effort and practitioner effort. The patient-doctor interchange is a classic example of moral hazard (Arrow (1963), Arrow (1985), Dranove and White (1987)) because the patient is unable to evaluate what the doctor is doing for her sake. Both principal and patient effort affect the outcome of a disease episode. Since the outcome of health investment is stochastic, effort cannot be imputed from the outcome. Every outcome is compatible with every level of input, though outcomes do give information about the likelihood of any given level of effort having been exerted.

In the specification we have introduced, the patient and the traditional healer both have incentives to exert effort, so although effort cannot be purchased in a perfect market, a contract exists for its provision. The provision of effort on the part of government and mission health centers is not quite as obvious.

\subsection{Organizational penalties}

Both government and mission health centers operate to serve the health of their clients; they are not profit making entities. Thus, though the practitioner does not have a direct incentive to exert effort, his employer has an incentive to induce effort. The employer of the practitioner does not observe the outcome of health care, but does observe other outcomes that give information about the effort of the provider. Practitioners produce both health for the patient and what we call organizational quality. This second output is observed by the employer. Records are kept of the various activities that go into producing health. Typically a selection of records are examined during a site visit. The patients' symptoms 
and complaints are part of all records and therefore procedures and records should follow protocols developed for each set of complaints. If a particular record or collection of records is determined to be in violation of standards the practitioner is punished in accordance with the gravity of the deviation. This method of ensuring quality is what we refer to as a penalty-based scheme.

When an organization can force a practitioner to produce high organizational quality it is also forcing the practitioner to exert medical effort, even though the patient's health is never observed. This system of incentives is very different from that of traditional healers. Because the employer does not observe the outcome of the treatment, the decision of whether or not to punish, or by how much, is independent of the effort of the patient.

The probability of being visited and observed, or of a record or set of records being examined, is fixed within and varies between organizations. Once the data from a particular consultation is observed, the organizational quality, $Q_{k}\left(a, \psi_{k}\right)$, is known with certainty. This is then compared to the required quality, $Q_{k}^{*}$ (which may differ by condition) and the punishment is proportional to this difference. The expected value of the penalty is

$$
g\left(a, \psi_{k}, j\right)=p_{j} \cdot k_{j}\left(Q_{k}^{*}-Q_{k}\left(a, \psi_{k}\right)\right)
$$

where $\psi_{k}$ are characteristics of the disease, $p_{j}$ is the probability, for any given organization $j$, of a record being examined and $k_{j}$ is the baseline penalty for organization $j \cdot p_{j}$ and $k_{j}$ cannot be identified separately thus we refer to the product as $K_{j}$.

We can construct the utility of the practitioner (who is risk neutral) and see that both traditional healers and providers at government and mission clinics have incentives to exert effort.

$$
\begin{aligned}
\text { Generally } U^{m} & =\underbrace{r_{j k} \omega_{i} \mu(a, b, \psi)}_{\text {contingent fee }}+\underbrace{d c_{j k}}_{\text {drugs }}+\underbrace{f c_{j}}_{\text {fixed }}-\underbrace{g\left(a, \psi_{k}, j\right)}_{\text {penalty }}-\underbrace{c(a)}_{\text {disutility }} \\
\text { Healer } U^{m} & =r_{j k} \omega_{i} \mu(a, b, \psi)+f c_{j}-c(a) \\
\text { Organizations } \quad U^{m} & =d c_{j k}+f c_{j}-g\left(a, \psi_{k}, j\right)-c(a)
\end{aligned}
$$


Penalties are important in our analysis because they provide the incentive to exert effort. We hypothesize that the penalty basis at mission centers is larger than at government centers (where all practitioners are protected from the most severe penalties because they are civil servants) and therefore practitioners at mission centers exert more effort for every condition than their government counterparts.

If there were perfect information about efforts the patient could choose those levels of both patient and medical effort that equated marginal cost to marginal benefit. However since neither effort is observable the patient will choose the level of her own effort that maximizes her utility given her expectation of the practitioner's effort. Medical effort at organizational providers is determined independent of the patient's actions. Traditional healers choose the optimal level of effort given their expectation of the patient's effort.

$$
\begin{gathered}
b^{*} \in \underset{b}{\operatorname{argmax}}\left(1-r_{j k}\right) \omega_{i} \mu\left(a^{\prime}, b, \psi\right)-f c_{j}-d c_{j k}-t c_{i j}-d(b) \\
a^{*} \in \underset{a}{\operatorname{argmax}} \omega_{i} r_{j k} \mu\left(a, b^{\prime}, \psi\right)-g\left(a, \psi_{k}, j\right)+f c_{j}+d c_{j k}-c(a)
\end{gathered}
$$

where $b^{\prime}$ is the practitioner's expectation of the patient's effort and $a^{\prime}$ is the patient's expectation of the practitioner's effort. Note that $r_{j k}$ and $K_{j}$ are never both greater than zero $\left(K_{j} \cdot r_{j k}=0 \forall j\right)$. The solution of this system of equations is the pair of efforts $\left\{a^{*}, b^{*}\right\}$ such that $a^{\prime}=a^{*}$ and $b^{\prime}=b^{*}$.

\subsection{Production in teams with unobservable effort}

This presentation has a strong parallel to the principle-agent model of production in teams advanced by Holmstrom (1982). His work shows that some relatively strong restrictions on the model are required in order to characterize the solution as a Nash non-cooperative game (i.e. with reaction functions as first order conditions). Here we explore those necessary specifications on the distribution of $X$.

Increases in health stock are produced by the joint effort of two agents; the patient and the practitioner. These two players form the team. We introduce a third player, the superprincipal, who declares incentive-compatible efforts for both agents (efforts that solve the 
system of equations 6 and 7), and pays them according to a contract. The super-principal does not exert effort but has the task of interpreting the information that she receives and executing the contract according to this information. To characterize the information she receives we need to make some assumptions about the distribution of the outcome of health investment.

We assume that there are two possible outcomes of any episode of illness, the patient can return to her previous state of good health or the patient can remain in her current state of health; recovery and no change. Thus $X=\bar{\mu}$ for full recovery and $X=\underline{\mu}=0$ for no change. The probability of either outcome is characterized by two binomial distributions, the full effort distribution $\phi_{\text {full }}$ and the no effort distribution $\phi_{\text {none }}$. At full effort (meant to invoke the idea that both parties do everything possible without regard to cost) the probability of full recovery is $p_{h}$, and at no effort the probability of full recovery is $p_{l}$.

A technology $e$ combines these two possible distributions. The expected outcome of health care is a spanning, by $e$, of the no effort and the full effort distributions.

$$
E(X)=\sum_{l=0, \bar{\mu}}\left(e \cdot \operatorname{prob}\left(X=l \mid \phi_{\text {full }}\right)+(1-e) \cdot \operatorname{prob}\left(X=l \mid \phi_{\text {none }}\right)\right)
$$

Note that we can arbitrarily assign a new variable $\mu=e \cdot \bar{\mu}$ and rewrite the above as

$$
E(X)=\sum_{l=0, \tilde{\mu}}\left(\frac{\mu}{\bar{\mu}} \cdot \operatorname{prob}\left(X=l \mid \phi_{\text {full }}\right)+\left(1-\frac{\mu}{\bar{\mu}}\right) \cdot \operatorname{prob}\left(X=l \mid \phi_{\text {none }}\right)\right)
$$

$\mathrm{E}(X)$ simplifies to $\mu\left(p_{h}-p_{l}\right)+p_{l} \cdot \bar{\mu}$. The expected increase in the number of healthy hours available for work is the probability of full recovery if no effort is exerted plus the premium on effort $\left(p_{h}-p_{l}\right)$ times the joint effort exerted.

Since the distribution of the outcome is a convex combination of two distribution functions it meets the Linear Distribution Function Condition (LDFC) as developed in Hart and Holmstrom (1987). LDFC implies that if we were to map out the information set available to the super-principal for each possible action of one agent (fixing the other agent's action) the set would be convex. The super-principal can only assign a unique payment 
(or expected payment) to each outcome, since the outcome is the only information she gathers. If the outcome is a convex set of the agent's effort then the marginal change in payments is guaranteed to have at most one tangency to the utility of the agent ${ }^{4}$. This allows us to characterize the incentive compatibility constraints as first order conditions. Henceforth, however, we will represent the expected outcome of health by $\mu$, as if $p_{h}$ were arbitrarily close to 1 and $p_{l}$ were arbitrarily close to $0^{5}$.

In the case of the interaction between a traditional healer and the patient the superprincipal is not an actual entity ${ }^{6}$. In the case of mission and government organizations the super-principal is the employer of the practitioner and observes certain other outcomes that depend only on the effort of the practitioner. The super-principal maximizes the utility of the patient subject to total cost and the participation constraint of the practitioner. Note that all actions must be incentive compatible, even the actions of the patient. Thus the problem can be represented as

$$
\begin{aligned}
\max _{r_{j k}, a, b} U^{s}=\left(1-r_{j k}\right) \omega_{i} \mu-\left(f c_{j}+d c_{j k}+t c_{i j}\right)-d(b)-T & \\
\text { subject to } & \\
a^{*} \in \underset{a}{\operatorname{argmax}} r_{j k} \omega_{i} \mu+f c_{j}+d c_{j k}-c(a)+T & \text { (I.C. medical) } \\
b^{*} \in \underset{b}{\operatorname{argmax}}\left(1-r_{j k}\right) \omega_{i} \mu-\left(f c_{j}+d c_{j k}+t c_{i j}\right)-d(b) & \text { (I.C. patient) } \\
r_{j k} \omega_{i} \mu+f c_{j}+d c_{j k}-c(a)+T=V_{m} & \text { (I.R. medical) } \\
\left(1-r_{j k}\right) \omega_{i} \mu-\left(f c_{j}+d c_{j k}+t c_{i j}\right)-d(b)>V_{p} & \text { (I.R. patient) }
\end{aligned}
$$

\footnotetext{
${ }^{4}$ For a distribution such as the normal, when the agent increases his effort the probability of any given outcome $X$, first increases and then decreases and the probability does not map out a convex set. The super-principal can align incentives so as to force the agent to chose an action whose marginal disutility of effort is exactly equal to the marginal change in payments but for the normal distribution there will be two actions that satisfy this condition and the principal can never force the agent to choose one over the other.

${ }^{5}$ Dropping $p_{l} \cdot \bar{\mu}$ is easily justified since, as a constant, it will fall out of the first order conditions and, since it does not vary by practitioner (the benefit to doing nothing is the same at all practitioners) will fall out of the conditional logit estimation. The factor $\left(p_{h}-p_{l}\right)$ is dropped anticipating data limitations. We collected data on the variance of the outcome of health as a whole (see section 3) not the variance of the full and no effort distributions. This simplification, though unfortunate, is not overly restrictive given that we assume both actors are risk-neutral and have utility only over the first, not the second or higher order moments.

${ }^{6}$ The super-principal can be represented by custom; custom might dictate incentive compatible actions of both parties in each case as well as the optimal share.
} 
where $T$ is the transfer from the super-principal to the practitioner, $V_{p}$ is the reservation utility of the patient and $V_{m}$ is the reservation utility of the practitioner. The practitioner's individual rationality constraint (I.R.) is binding and we can therefore substitute it into the super-principal's objective function. We have justified the use of the relaxed incentive compatibility (I.C.) constraints and since all players are risk neutral we can reduce the problem to maximizing the expectation of the outcome and we get:

$$
\max _{r_{j k}, a, b} U^{s}=\omega_{i} \mu-t c_{i j}-d(b)-c(a)-V_{j}
$$

subject to

$$
\begin{gathered}
r_{j k} \omega_{i}\left(\frac{\partial \mu}{\partial a}\right)-\frac{\partial c(a)}{\partial a}=0 \\
\left(1-r_{j k}\right) \omega_{i}\left(\frac{\partial \mu}{\partial b}\right)-\frac{\partial d(b)}{\partial b}=0 \\
\left(1-r_{j k}\right) \omega_{i} \mu-\left(f c_{j}+d c_{j k}+t c_{i j}\right)-d(b)>V_{p}
\end{gathered}
$$

\subsubsection{Balanced budgets}

We begin by considering the case of the interaction between the patient and a traditional healer; $K_{j}=0$. Note that the first best solution from the point of view of the superprincipal is the point where the marginal benefit of effort is equal to its marginal cost;

$$
\begin{aligned}
& \omega_{i}\left(\frac{\partial \mu}{\partial a}\right)-\frac{\partial c(a)}{\partial a}=0 \\
& \omega_{i}\left(\frac{\partial \mu}{\partial b}\right)-\frac{\partial d(b)}{\partial b}=0
\end{aligned}
$$

But the super-principal can only require effort compatible with the incentives of the practitioner and the patient as defined by the incentive compatibility constraints equations $10^{\prime}$ and $11^{\prime}$. $10^{\prime}$ and $11^{\prime}$ are equal to 14 and 15 if $r_{j k}=\left(1-r_{j k}\right)=1$, which it cannot be. When the payments to the patient and the practitioner must always sum to the value of the output (the super-principal is required to redistribute all gains from the outcome), then $r_{p}+r_{m}=1$ (in this case $\left(1-r_{j k}\right)+r_{j k}=1$ ) and the principal cannot achieve the first best solution. 
Proposition 1: A linear sharing rule cannot achieve the full information solution in the case of unobservable effort. Proof is above.

Given that the full information solution is not obtainable, is the introduction of a sharing rule an improvement over the solution without a sharing rule?

Proposition 2: With unobservable efforts as above any sharing rule $0<r_{j k}<1$ gives a solution strictly superior to either $r_{j k}=0$ or $r_{j k}=1$. For proof see Appendix A.

We cannot achieve the first-best solution with a sharing rule but we can improve on the solution that would obtain without a sharing rule.

\subsubsection{Unbalanced budgets, Super-Principals and Institutions}

Balanced budgets and super-principals are a related concept in this exposition. In a oneperiod game two agents could not sustain a contract that did not have a balanced budget. They might agree to dispose of outcome (by burning money for example) but this would be renegotiated were such an action ever called for and is therefore not a credible agreement. When the super-principal is not an actual third party all budgets must be balanced.

If the super-principal is an actual entity she can inject or remove value from the game; the payments do not need to sum to the total value. By breaking the budget balance the super-principal can achieve the first best solution to the game. Instead of a sharing rule

$\left\{r_{m}, r_{p}\right\}$, where $r_{p}=1-r_{m}$, choose $r_{p}=1$ and $r_{m}=1$. Examining again equations $10^{\prime}$ and $11^{\prime}$ it should be clear that such a rule will achieve the first best solution. Note that the super-principal can then extract the expected value of these payments from the two parties without changing either incentive compatibility constraint. This is not a balanced budget because, though the sum of payments might be equal to the total value in expectation, they do not equal the total value in each case.

In this paper we advance the concept of the institution as a super-principal. The role of the organization within the institution of modern health care is to break budget balance and induce effort. They do this by punishing the practitioner. Any punishment of the practitioner is not a balanced action because the value of the punishment is not passed on to the patient. The punishment of practitioners through penalties as outlined 
in section 2.2 does not achieve the first best solution because the super-principal never observes the actual outcome of the treatment. If the super-principal observed the outcome of treatment and acted in the interests of patients the sharing rule of the traditional healer would never be superior to the punishment of budget-breaking institutions.

Institutions are also important for the contract offered at the traditional healer. Verifiable, not just observable, outcomes are essential to the mechanism of a contingent-payment contract. If patients can lie about the outcome of treatment a contingent-payment contract cannot be maintained. We discovered that there is a strong institution for the enforcement of truth-telling. Without exception patients will not lie to traditional healers about the outcome of treatment for fear that the cure will be revoked by spirits, or that a far worse illness will befall them (see Leonard (1998)). Traditional healers expressed very little concern about collecting the money due them and all said that patients were always honest. Patient believe outcomes can be verified by the super-principal and act accordingly.

Unobservable efforts introduce an inefficiency in exchange. Health care in Cameroun exhibits two institutions that address this problem. Neither achieve the full information solution, but each improves upon the solution in the absence of contracts or institutions. Eswaran and Kotwal (1985) show, using simulation, that three different agricultural contracts (share-cropping, wage labor and rented land) can co-exist in a situation of imperfect factor markets and show that each contract dominates the other for certain crops or production technologies. Analogously we view treatments for different diseases as different technologies and show that both fee-for-service (similar to wage labor) and contingentpayment (similar to share-cropping) can co-exist.

\subsection{Functional Forms}

To continue we specify functional forms. The expected value of investment in health care is a Cobb-Douglass production function $\mu=\left(a \pi_{j k}\right)^{\gamma_{k}}\left(b \eta_{i}\right)^{\alpha_{k}}$ where $\alpha_{k}+\gamma_{k}<1$. $\gamma_{k}$ is the responsiveness of a disease to patient effort, $\pi_{j k}$ is the skill of the practitioner, $\alpha_{k}$ is the responsiveness of the disease to patient effort and $\eta_{i}$ is the efficiency of the patient at 
transforming effort into health.

We chose simple forms for disutility of effort where, $c(a)=a$ and $d(b)=b$. Recall the specification of the penalty, $g\left(a, \psi_{k}, j\right)=K_{j}\left(Q_{k}\left(a, \psi_{k}\right)_{k}^{*}-Q_{k}\left(a, \psi_{k}\right)\right)$. We chose the functional form of $Q_{k}\left(a, \psi_{k}\right)$ in anticipation of a simple functional specification for $a^{*}$. $\zeta_{k}$ is a scalar that varies by disease condition.

$$
Q_{k}\left(a, \psi_{k}\right)=\ln (a) \cdot \zeta_{k}
$$

For visits to the traditional healer with the preceding functional forms we can reduce equations 10 and 11 by assuming a Nash non- cooperative equilibrium and get

$$
\begin{gathered}
a^{*}=\left(\frac{\left(\left(1-r_{j k}\right) \eta_{i} \alpha_{k}\right)^{\alpha_{k} \pi_{j k}} \gamma_{k} \omega_{i}}{\left(r_{j k} \gamma_{k}\right)^{\alpha_{k}-1}}\right)^{\frac{1}{1-\alpha_{k}-\gamma_{k}}} \\
b^{*}=\left(\frac{\eta_{i}{ }^{\alpha_{k}}\left(r_{j k} \gamma_{k} \pi_{j k}\right)^{\gamma_{k}} \omega_{i}}{\left(\left(1-r_{j k}\right) \alpha_{k}\right)^{\gamma_{k}-1}}\right)^{\frac{1}{1-\alpha_{k}-\gamma_{k}}}
\end{gathered}
$$

Patient utility is expressed, in equation 18 as a function only of patient, practitioner, and disease characteristics. Note that utility is a strictly increasing function of the opportunity cost of time $\left(\omega_{i}\right)$, the patient efficiency at transforming health care into health $\left(\eta_{i}\right)$ and practitioner skill $\left(\pi_{j k}\right)$.

$$
\begin{array}{r}
E\left(U^{p}\right)=\left(\omega_{i} \eta_{i}^{\alpha_{k}} \pi_{j k} \gamma_{k}\right)^{\frac{1}{1-\alpha_{k}-\gamma_{k}}}\left(\left(\left(1-r_{j k}\right)^{\left(1-\gamma_{k}\right)} \alpha_{k} \alpha_{k}\left(r_{j k} \gamma_{k}\right)^{\gamma_{k}}\right)^{\frac{1}{1-\alpha_{k}-\gamma_{k}}}-\right. \\
\left.\left(\left(r_{j k} \gamma_{k}\right)^{\gamma_{k}}\left(\left(1-r_{j k}\right) \alpha_{k}\right)^{\left(1-\gamma_{k}\right)}\right)^{\frac{1}{1-\alpha_{k}-\gamma_{k}}}\right)-\left(f c_{j}+d c_{j k}+t c_{i j}\right)
\end{array}
$$

A closed form solution for the optimal share, $r_{j k}{ }^{*}$, is not obtainable, but the solution can be shown to depend only on $\gamma_{k}$ and $\alpha_{k}$.

$$
\begin{array}{r}
r_{j k}{ }^{*} \in \underset{r_{j k}}{\operatorname{argmax}}\left(\left(\left(1-r_{j k}\right) \alpha_{k}\right)^{\alpha_{k}}\left(r_{j k} \gamma_{k}\right)^{\gamma_{k}}\right)^{\frac{1}{1-\alpha_{k}-\gamma_{k}}}- \\
\left(\left(\left(1-r_{j k}\right) \alpha_{k}\right)^{\alpha_{k}}\left(r_{j k} \gamma_{k}\right)^{1-\alpha_{k}}\right)^{\frac{1}{1-\alpha_{k}-\gamma_{k}}}- \\
\left(\left(r_{j k} \gamma_{k}\right)^{\gamma_{k}}\left(\left(1-r_{j k}\right) \alpha_{k}\right)^{1-\gamma_{k}}\right)^{\frac{1}{1-\alpha_{k}-\gamma_{k}}}
\end{array}
$$


For organizational providers $a^{*}$ is independent of $b$ and characteristics of the patient but $b^{*}$ does depend on $a^{*}$. Patient utility is an increasing function of $K_{j}, \zeta_{k}, \pi_{j k}, \eta_{i}$ and $\omega_{i}$.

$$
\begin{array}{r}
a^{*}=K_{j} \cdot \zeta_{k} \\
b^{*}=\left(\omega_{i}\left(\pi_{j k} \gamma_{k}\right)\left(\left(K_{j} \zeta_{k}\right)^{\gamma_{k}}\right)\left(\eta_{i}{ }^{\alpha_{k}}\right) \alpha_{k}\right)^{\frac{1}{1-\alpha_{k}}} \\
E\left(U^{p}\right)=\left(\omega_{i}\left(K_{j} \zeta_{k} \pi_{j k}\right)^{\gamma_{k}}\left(\alpha_{k} \eta_{i}\right)^{\alpha_{k}}\right)^{\frac{1}{1-\alpha_{k}}}\left(1-\alpha_{k}\right)-\left(f c_{j}+d c_{j k}+t c_{i j}\right)
\end{array}
$$

\section{Data}

Data on patient behavior in the face of illness were collected in Mbonge sub-division, in the South-West province of Cameroun. The sub-division is entirely rural. This area was chosen because of the presence of a German aid project that insured a consistent, reasonably-priced drug supply in all government health centers and hospitals.

40 villages were randomly chosen and 20 randomly selected households from each village were interviewed. Data were collected on all members of the household. There were 681 illness episodes reported within the 1 month recall period out of 4,489 individuals represented. Of these, 548 visited one of the five types of providers we are studying and we have complete and consistent data for 535. All reported visits are first contacts. Referrals, second opinions, and follow-up visits are not included in this analysis. Furthermore we do not consider normal pregnancy or delivery to be an illness episode. The 'other practitioners' category included (in order of frequency): drug peddlers; pharmacists; neighbors; private hospitals: private clinics and parastatal hospitals.

\subsection{Patient level data}

$\psi_{i}\left\{\eta_{i}, \omega_{i}\right\}$

We do not observe the opportunity cost of healthy time, nor the patient's efficiency at converting health inputs into health. We substitute for these two variables an aggregation of the data that we do observe and hypothesize is related to the opportunity cost or efficiency. $\omega_{i}$ and $\eta_{i}$ are then estimated within the structural estimation. 
We substitute for $\omega_{i} M$ individual characteristics $w_{i}$ such that $\omega_{i}=\sum_{m} W_{m} \cdot w_{i m}$ with $\left\{W_{0} \ldots W_{M}\right\}$ to be estimated within the structural estimation. $w_{i}$ includes a constant, the reported wage converted to a weekly rate and, for individuals who are of working age, but report no income (mostly housewives) the total family income.

We substitute for $\eta_{i} L$ individual characteristics $e_{i}$, such that $\eta_{i}=\sum_{l} E_{l} \cdot e_{i l}$ with $\left\{E_{0} \ldots E_{L}\right\}$ to be estimated. $e_{i}$ includes a constant, the log of family wealth, age, age squared, gender and dummy variables for occupations. We include the age, gender and education level of the individual who looked after the patient for episodes involving children and the old or infirm. When a patient looked after herself these variables reflect her own characteristics.

\subsection{Provider level data}

$\psi_{j}\left\{r_{j k}, K_{j}, f c_{j},\right\}$

$r_{j k}{ }^{*}$ is determined endogenously in the empirical estimation. All other shares are fixed at 0 . The penalty bases for government and mission centers are determined in the estimation. Fixed costs are known from the data and since they do not vary by disease or individual we can assign the known fixed cost to every center. Government clinics and hospitals have fixed costs over the whole sample; mission costs vary from center to center and we use the average. Fixed fees for the traditional healer are deduced from average fees paid at the time of consultation.

\subsection{Joint determination}

Drug costs $d c_{j k}$ depend on the practitioner and the disease. Travel costs $t c_{i j}$ are determined by the practitioner and the individual, i.e. origin and destination.

\subsubsection{Drug Costs}

We cannot use the reported cost of drugs as the expected cost of drugs because we do not observe the cost at centers not visited and we know that drug costs are not the same across centers, even for the same disease. The cost of drugs at mission centers is higher 
than the cost at government centers because the government subsidizes drugs. The cost of filling a prescription at hospitals is higher than at clinics because there are more drugs and diagnostic tests available. The prescription filled at a hospital might be more effective than that filled at a clinic, and it costs more. Note that at traditional healers the drug cost is always zero whereas the same disease would require drug purchases at any other center.

Furthermore there is selection bias in reported drug costs. There is correlation between the type of disease and the quantity and type of drugs purchased, and individuals choose centers in part according to the disease. In order to estimate the cost of drugs at each center we hypothesize that the drug cost is a function of characteristics of the disease and that costs are related across centers by a fixed ratio.

$$
d c_{j k}=\Delta_{k} \cdot d c_{k}=\Delta_{k} \cdot \prod_{n} z_{i n}^{\beta_{n}} \cdot \prod_{l} e_{k l}^{\alpha_{l}}
$$

$d c_{j k}$ is the cost at any given center, and $d c_{k}$ is a numeraire drug cost for each disease. The cost at each center is related to the numeraire cost by a ratio $\Delta_{k}$, and the numeraire cost is a function of individual characteristics and disease characteristics. We set the ratio between a government center and the numeraire cost to 1 . With a large set of observed drug costs we can estimate $d c_{k}$ and $\Delta_{k}$. Results of the log-linear regression are reported in Leonard (1997).

\subsubsection{Travel Costs}

We have data for each village on the distance and total taxi cost to most major hospitals and clinics. Taxi costs in this area are determined on a per kilometer basis, depending on the quality of the road. Thus, using a large set of known taxi costs we have estimated a taxi cost from every village to the closest of each of the four organizational providers. Although we have data on distances traveled to visit a traditional healer, we do not know the location of every traditional healer in the sample area is located so we cannot reliably calculate the cost of the counter-factual visit. The average distance traveled to visit a 
traditional healer is small so we normalize this distance to zero. Note that though we use taxi costs, not every patient took a taxi.

\subsection{Disease Level Data}

$\psi_{k}\left\{\tilde{\gamma}_{k}, \tilde{\alpha}_{k}, \tilde{\pi}_{j k}, \sigma_{k}\right\}^{7}$

We collected information from respondents on the characteristics of the episode from which they suffered: all symptoms they experienced; the self-declared severity of the disease; the number of days sick before seeking care; and the number of those days the patient was bedridden. With these characteristics, the age and sex of the individual and information about endemic diseases in the area, we carefully considered each case and then ranked each in the following categories ${ }^{8}$.

\section{Responsiveness to Medical Effort $\tilde{\gamma}_{k}$}

Responsiveness to medical effort is the degree to which outcome depends on the effort of the practitioner.

\section{Responsiveness to Patient Effort $\tilde{\alpha}_{k}$}

Is there a critical role for the patient in her treatment?

\section{Benefit of skill and capacity $\tilde{\pi}_{j k}$}

There are three levels of skill and capacity that patients can choose between, with the benefit at a higher level facility always at least as high as the benefit at lower level facilities ${ }^{9}$.

- Informally trained practitioner These are people who are in the health care profession and may have practiced for many years, but who never completed a formal medical training program. Their experience can be sizable but it will not be based on a foundation of western medical training. Common drugs are available to them.

\footnotetext{
${ }^{7}$ Symbols such as $\gamma_{k}$ are represented here as $\tilde{\gamma}_{k}$, for example, to indicate that it will be transformed by a constant factor in the empirical investigation. Thus $\gamma_{k}=\beta_{l} \cdot \tilde{\gamma}_{k}$.

${ }^{8}$ All coding was blind of provider chosen and diagnosis.

${ }^{9}$ Patients claim that there are diseases for which traditional healers have more skill. We are assuming that their perceived skill comes instead from effort.
} 
- Formally trained personnel in a clinic These practitioners have some formal training and work in a facility that has a basic drug supply, beds, IV equipment and a delivery room but not much more.

- Highly trained personnel in a hospital These practitioners have advanced formal training and practice in a hospital with a much greater supply of drugs and equipment for surgery, long term care, etc. General practitioners would also be expected to have reasonable access to the services or advice of specialists.

\section{Variance of Outcomes $\sigma_{k}$}

The range of possible outcomes.

Scores of 0 (low) to 10 (high) were used for all scales. Since the analysis is sensitive to the scores given to each case we had 2 doctors and one nurse (all experienced in rural tropical medicine) score all the cases using the definitions above. We found that our scoring correlated better with the other three than any of the other three correlated with the others - ours was a median of sorts. Therefore we perform the analysis with our scores that are justified and documented in Leonard (1997).

In Figure 1 we show how a variety of disease examples fall into the grid of responsivenesses to effort. Keep in mind that the full model examines variations in disease severity and the medical skill needed as well whereas this figure treats these as constant. (Overlaying this grid is the division into choices of providers for the average individual at the average skill and severity of disease from the structural estimation). It is an important feature of this model that one can predict that certain health care practitioners will see some types of diseases more frequently than others. In fact there are recognizable patterns in the types of conditions reported at all centers and this theory is an explanation for such patterns as well as a method of predicting them.

\subsection{Organizational Quality Factor}

We estimate $\zeta_{k}$ by an aggregation of disease characteristics, $z_{k}$. Thus $\zeta_{k}=\sum_{n} H_{l} \cdot z_{k l}$, with $\left\{H_{0} \ldots H_{N}\right\}$ to be estimated. $z_{k}$ includes a constant, the responsiveness to medical 


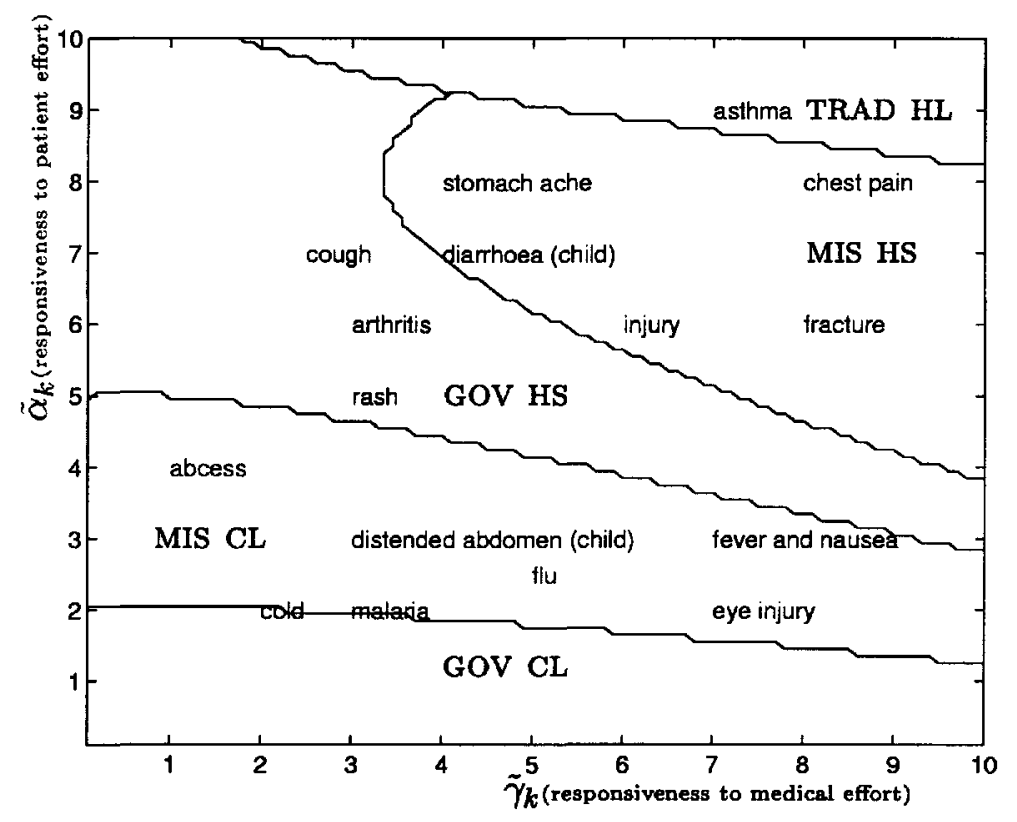

Figure 1: Two dimensional projection of disease characteristics

effort, the variance of the outcome, the product of responsiveness and variance and the skill of a provider at a hospital.

\section{Empirical analysis}

We know the characteristics of the disease and now proceed to solve for the parameters of the non-cooperative game that produces a pattern of choices that best resembles the actual pattern of choices. The empirical estimation is similar to the McFadden conditional logit in that we estimate one vector of coefficients for all individuals and choices (practitioners). 
Recall the model; when $K_{j}=0$ or traditional healers.

$$
\begin{aligned}
r_{j k}^{*} \in & \underset{r_{j k}}{\operatorname{argmax}}\left(\left(\left(1-r_{j k}\right) \alpha_{k}\right)^{\alpha_{k}}\left(r_{j k} \gamma_{k}\right)^{\gamma_{k}}\right)^{\frac{1}{1-\alpha_{k}-\gamma_{k}}}- \\
& \left(\left(\left(1-r_{j k}\right) \alpha_{k}\right)^{\alpha_{k}}\left(r_{j k} \gamma_{k}\right)^{1-\alpha_{k}}\right)^{\frac{1}{1-\alpha_{k}-\gamma_{k}}}- \\
& \left(\left(r_{j k} \gamma_{k}\right)^{\gamma_{k}}\left(\left(1-r_{j k}\right) \alpha_{k}\right)^{1-\gamma_{k}}\right)^{\frac{1}{1-\alpha_{k}-\gamma_{k}}} \\
E\left(U^{p}\right)= & \left(\omega_{i} \eta_{i}{ }^{\alpha_{k}} \pi_{j k} \gamma_{k}\right)^{\frac{1}{1-\alpha_{k}-\gamma_{k}}} \\
& \left(\left(\left(1-r_{j k}{ }^{*}\right)^{\left(1-\gamma_{k}\right)} \alpha_{k} \alpha_{k}\left(r_{j k}{ }^{*} \gamma_{k}\right)^{\gamma_{k}}\right)^{\frac{1}{1-\alpha_{k}-\gamma_{k}}}-\right. \\
& \left.\left(\left(r_{j k}{ }^{*} \gamma_{k}\right)^{\gamma_{k}}\left(\left(1-r_{j k}{ }^{*}\right) \alpha_{k}\right)^{\left(1-\gamma_{k}\right)}\right)^{\frac{1}{1-\alpha_{k}-\gamma_{k}}}\right)-\left(f c_{j}+d c_{j k}+t c_{i j}\right)
\end{aligned}
$$

When $r_{j k}=0$ or organizational providers

$$
E\left(U^{p}\right)=\left(\omega_{i}\left(K_{j} \zeta_{k} \pi_{j k}\right)^{\gamma_{k}}\left(\alpha_{k} \eta_{i}\right)^{\alpha_{k}}\right)^{\frac{1}{1-\alpha_{k}}}\left(1-\alpha_{k}\right)-\left(f c_{j}+d c_{j k}+t c_{i j}\right)
$$

And for all providers 10

$$
\begin{aligned}
& \text { patient efficiency } \quad \eta_{i}=\sum_{l} E_{l} \cdot e_{i l} \\
& \text { opportunity cost of healthy time } \quad \omega_{i}=\sum_{m} W_{m} \cdot w_{i m} \\
& \text { organizational quality factor } \quad \zeta_{k}=\sum_{n} H_{n} \cdot z_{k_{n}} \\
& \text { responsiveness to medical effort } \quad \gamma_{k}=\mathrm{B}_{2} \cdot \tilde{\gamma}_{k} \\
& \text { responsiveness to patient effort } \quad \alpha_{k}=\mathrm{B}_{2} \cdot \tilde{\alpha}_{k} \\
& \text { provider skill } \quad \pi_{j k}=\left(\tilde{\pi}_{j k}\right)^{\mathrm{B}_{3}}
\end{aligned}
$$

We observe the characteristics of the disease, $\tilde{\gamma}_{k}, \tilde{\alpha}_{k}, \tilde{\pi}_{j k}, \sigma_{k}$, the characteristics of the individual, $w_{i}, e_{i}$, the fixed cost, $f c_{j}$, drug costs $d c_{j k}$, travel costs, $t c_{i j}$, and the choice of practitioner, $\delta$. Costs and incomes are in CFA 1,000

\footnotetext{
${ }^{10}$ We multiply the responsiveness by a factor because a test of $B_{2}=0$ is a test that efforts are not significant in the determination of outcome $\left(B_{2}=0\right.$ implies $\left.\mu=1\right)$. On the other hand we raise skill to a power because $B_{3}=0$ implies that skill is invariant across practitioners.
} 
Using a maximum likelihood patterned on the McFadden Conditional Logit we estimate the following parameters; the penalty basis for the mission centers, $K_{\text {mission }}$, and the penalty basis for hospitals $K_{\text {hospital }}$ (we fix the penalty basis for government clinics at 1 ); the parameters for the aggregation of $\eta_{i}, \vec{E}$; the parameters for the aggregation of $\zeta_{k}, \vec{H}$; the parameters for the aggregation of $\omega_{i}, \vec{W}$; the factor for responsiveness, $\mathrm{B}_{2}$; the exponent for skill, $\mathrm{B}_{3}$; and the standard deviation of utility $\mathrm{B}_{1}{ }^{11}$.

$r_{j k}{ }^{*}, a$ and $b$ are endogenously determined.

The likelihood is formed as follows.

$$
\begin{gathered}
l=\sum_{i=1}^{t} \sum_{j=1}^{5} \log \left(P_{i j}\right)^{\delta_{i j}} \\
P_{i j}=\frac{\exp \left(U_{i j}\right)}{\sum_{l=1}^{5} \exp \left(U_{i l}\right)}
\end{gathered}
$$

Where $\delta_{i j}=1$ when provider $\mathrm{j}$ was chosen and 0 otherwise.

Using a Newton-Raphson algorithm we maximize the log-likelihood, solving for the optimal sharing rule within each evaluation of the likelihood.

The asymptotic covariance matrix of the estimated parameters $(\hat{B})$ is estimated from the variance matrix of the first derivative vector.

$$
[\hat{\hat{I}}(\hat{\beta})]^{-1}=\left[\sum_{i} \hat{g}_{i} \hat{g}_{i}^{\prime}\right]^{-1} \text { where } \quad \hat{g}_{i}=\frac{\partial\left(l_{i}\right)}{\partial(\hat{\beta})}
$$

Where $l_{i}$ is the log likelihood for each observation. We approximate $\hat{g}_{i}$ by finite differences. As a check on the validity of the conditional logit we performed a conditional probit estimation with a simulated multivariate normal distribution. The results are reported in Appendix B. Each estimated coefficient except the error of the utility is contained within 1 standard deviation of the conditional logit estimate. This suggests that, given the structural form of utility, our choice of conditional logit is relatively robust.

\footnotetext{
${ }^{11}$ We can determine the magnitude of the error term because the coefficient for costs is set to 1 .
} 


\subsection{Results}

The estimated coefficients and their corresponding z-tests are reported in Table 1.

Table 1: Conditional Logit Estimated Coefficients

\begin{tabular}{|c|c|c|c|c|}
\hline & $\begin{array}{l}\text { log likelihood }-783.12 \\
\text { variable }\end{array}$ & coefficient & std err & z-test \\
\hline & $\mathrm{B}_{1}$ standard error & 11.61 & 1.338 & 8.68 \\
\hline & $B_{2}$ responsiveness factor & 0.5503 & 0.1111 & 4.95 \\
\hline & $B_{3}$ skill exponent & 0.6475 & 0.4989 & 1.30 \\
\hline & alty function & & & \\
\hline & $K_{\text {mission }}$ (mission penalty basis) & 0.5434 & 0.2661 & 2.04 \\
\hline & $K_{\text {hospital }}$ (hospital penalty basis) & 1.079 & 0.4984 & 2.17 \\
\hline & $H_{0}$ & -8.095 & 2.279 & -3.55 \\
\hline & $H_{1}\left(\gamma_{k}\right)$ & 0.695 & 0.2303 & 3.02 \\
\hline & $H_{2}\left(\sigma_{k}\right)$ & 1.707 & 0.5523 & 3.09 \\
\hline & $H_{3}\left(\gamma_{k} \cdot \sigma_{k}\right)$ & -0.184 & 0.07 & -2.75 \\
\hline & $H_{4}\left(\pi_{h, k}\right)$ & 0.118 & 0.1202 & 0.98 \\
\hline$\eta_{i}$ & patient efficiency at transforming he & lth inputs & & \\
\hline & $\mathrm{E}_{0}$ constant & 5.695 & 4.517 & 1.26 \\
\hline & $\mathrm{E}_{1}$ family wealth (ln) & 1.133 & 0.7817 & 1.45 \\
\hline & ent & & & \\
\hline & $\mathrm{E}_{2}$ age & 0.4395 & 0.161 & 2.73 \\
\hline & $\mathrm{E}_{3} \mathrm{age}^{2}$ & -0.0042 & 0.0019 & -2.29 \\
\hline & $\mathrm{E}_{4}$ gender $($ female $=1)$ & -0.935 & 1.482 & -0.63 \\
\hline & $\mathrm{E}_{5}$ student & -5.885 & 2.127 & -2.77 \\
\hline & $\mathrm{E}_{6}$ farmer & -5.206 & 2.073 & -2.51 \\
\hline & $\mathrm{E}_{7}$ businessman or civil servant & 6.276 & 3.549 & 1.77 \\
\hline & vidual responsible for patient & & & \\
\hline & $\mathrm{E}_{8}$ age & -0.1312 & 0.057 & -2.28 \\
\hline & $\mathrm{E}_{9}$ gender $($ female $=1)$ & -3.542 & 1.678 & -2.11 \\
\hline & $\mathrm{E}_{10}$ education & -0.4808 & 0.2283 & -2.11 \\
\hline$\omega_{i}$ & wage & & & \\
\hline & $W_{0}$ (constant) & 41.73 & 12.34 & 3.38 \\
\hline & $W_{1}$ (reported wage) & 0.7041 & 0.5447 & 1.29 \\
\hline & $W_{2}$ (family income for non-workers) & 0.4232 & 0.8224 & 0.51 \\
\hline
\end{tabular}

The likelihood ratio test of the restriction that $\omega_{i}, \eta_{i}$, and $\zeta_{k}$ are explained only by constant terms (all coefficients $W, E$, and $H$ other than the constant terms are equal to zero) is rejected with a p-value of less than 0.00001 ( $L R=54$ with $16 \mathrm{df}$ ).

Individual tests of significance on the weekly wage and the family income for non- 
workers $\left(\mathrm{W}_{1}, \mathrm{~W}_{2}\right)$ fail to reject the hypothesis that they are equal to zero. The LR of the test of the joint hypothesis that $W_{1}=W_{2}=0$ is rejected at a p-value of 0.0963 (LR = 4.66 with $2 \mathrm{df}$ ). Individual income or family wealth play a role in the determination of the opportunity cost of time, but we do not have strong evidence of the manner in which the opportunity cost of healthy time varies across individuals.

We can reject the hypothesis that effort at organizational providers is constant, varying between but not within centers (LR test of all $H$ except constant equal to zero rejected with p-value $<0.0001 ; L R=33.76$ with $4 \mathrm{df}$ ). We can also reject the hypothesis that efforts do not vary between centers as both the mission penalty basis and the hospital penalty basis are significantly different from zero (where zero would imply equality with the government clinic). The model's estimates imply that a protocol violation committed at a government hospital would result in a punishment of over twice the expected value of the punishment that would result if the same violation had been committed at a government clinic. This could come from either an increased frequency of monitoring, or an increased penalty when a violation is detected. A mission clinic punishes the same violation at about $154 \%$ of the expected value of a violation at a government clinic. The expected value of the punishment for a violation at a mission hospital is $2.62(1+0.54+1.08)$ times greater than at a government clinic. We believe that the majority of the increased penalty basis at hospitals over clinics ( $\left.K_{\text {hospital }}\right)$ comes from increased monitoring (hospitals are all in major towns) and that the majority of the increased penalty basis at mission centers $\left(K_{\text {mission }}\right)$ comes from increased sanctions or decreased bonuses.

The joint test that all coefficients $E_{1}$ through $E_{10}$ are zero is rejected with a p-value of 0.002 ( $\mathrm{LR}=27.66,10 \mathrm{df}$ ). Age is clearly an important determinant of the ability of a patient to transform health into health care both for the patient and for the person responsible for the patient. We had included this second individual to try and capture some of the dynamic of patient-practitioner interactions. Patients can improve their chance of recovery both during the examination and during the treatment. A person with a higher level of education would be more able, and might feel freer, to interact with the practitioner by asking questions or insisting he listen to descriptions of symptoms. It 
Table 2: Endogenously determined provider efforts

\begin{tabular}{l|l|l|l|l} 
provider & average & median & minimum & maximum \\
\hline \hline traditional healer & 7.32 & 3.00 & 0.024 & 188.7 \\
government clinic & 0.936 & 0.53 & 0.004 & 13.9 \\
government hospital & 1.946 & 1.10 & 0.007 & 28.91 \\
mission clinic & 1.444 & 0.82 & 0.006 & 21.46 \\
mission hospital & 2.454 & 1.39 & 0.009 & 36.46 \\
\hline all units are 1,000 CFA & \multicolumn{4}{|l}{}
\end{tabular}

appears that if there is a disadvantage to being a woman in the search for good health care it comes from this interaction (almost all practitioners are male). Students and farmers appear at a disadvantage and the small number of businessmen and civil servants (mostly retired) in our sample are at a great advantage in the search for health care.

The factor for responsivenesses is clearly significant though that for skill is not. This could be caused by any of three things. Skill might not matter in the search for health care (something we consider unlikely), or patients might not value skill in the same manner as practitioners (codings were done from a medical perspective) or our codings were too crude to capture this effect properly. Given the p-value of 0.19 corresponding to the $\mathrm{z}$-test, suggesting some, but not overwhelming confidence in the coefficient, we think the third of these explanations is the most likely.

$a, b$ and $r_{j k}{ }^{*}$ are solved endogenously. $b$ has no natural scale but $a$ does. $a$ for the traditional healer is solved by determining the willingness to exert effort in return for compensation measured in money terms. Assuming that traditional healers and organizational providers face the same disutility functions we can assign a scale to all providers efforts.

The variance of effort provided at traditional healers is higher at organizational providers because it depends on characteristics of the patient as well as characteristics of the disease. Table 2 shows the advantage that traditional healers hold over other providers. Though they have lower levels of skill, they exert much higher levels of effort on the behalf of their patients. This result parallels in the comments of patients in focus group interviews who repeatedly pointed out that traditional healers took the time to properly examine them.

For a visit to a government center, practitioners exert effort for which they expect to be 
compensated on average $940 \mathrm{CFA}$ at a clinic and 1,900 CFA at a hospital. The respective median compensations were $530 \mathrm{CFA}$ and 1,100 CFA. We point out these numbers because we have prior beliefs about their range. The expected compensations (or disutilities) compare to fees of $100 \mathrm{CFA}$ at clinics and $600 \mathrm{CFA}$ at hospitals. Clearly the fees are much smaller than the effort exerted, but the fees were never intended to cover costs. We note that in another sub-division in which we performed a pre-test of this survey, government centers were supposed to be free, but informally fees were required. The fees charged varied from clinic to clinic, but based on patient declaration of what they paid we estimate that the fees were at least $500 \mathrm{CFA}$ at clinics and often as high as 1,000 CFA. Since fees were set by practitioners their magnitude can be expected to carry more information about expected compensations and they appear to be consistent with the compensations the model predicts.

The share of value paid to traditional healers varied between $32 \%$ and $70 \%$. The value of the average predicted payment to traditional healers was 44,000 CFA. This is skewed by a few large payments with the largest being 857,000 CFA (about 430 USD). We did not observe any payments of this magnitude in the survey. However, we believe it is not an unreasonable result because we only observed payments that were made at the most 1 month after the beginning of treatment. Interviews with healers and patients suggest that only a small portion of payments are made in such a short period of time. Indeed the largest payment we heard of in interviews with healers was that of two cows for a previously barren woman who gave birth and that payment was presented on the seventh birthday of the child. The value of two cows easily contains our maximum estimated payment.

That the predicted payments to traditional healers and the required compensations of government practitioners are well within the range of our priors, when we included no mechanism in the estimation to bind them, is taken as a sign of confidence in our results.

The average value of a visit (before taking into account that patients choose the provider with the maximum benefit) was about 38,000 CFA or 17 USD. The value of health care is more extensively investigated in the following section. At the margin we 
calculate that $100 \mathrm{CFA}$ worth of effort on the part of a practitioner at government clinics is worth 1,600 CFA to the median patient. At government hospitals $100 \mathrm{CFA}$ worth of effort is worth $900 \mathrm{CFA}$ to the median patient. This is a direct result of unobservable efforts.

This gap between the cost of quality health care and its value suggests an opportunity for side-payments. Indeed many government-run health services unofficially require sidepayments. However there is no sense among among consumers that we spoke to that quality is better at centers that require side-payments whereas they all believe quality is higher at mission centers. If there is imperfect information in the provision of health care then this observation should be expected. When the outcome is unverifiable there is no credible contract for the provision of quality health care that is not backed up by the threat of penalty by a super-principal. Side-payments do purchase unobservable effort.

We do not investigate the role of side-payments in this work, but we cite one interesting result from a work on similar data from the same area. Ndeso-Atanga (forthcoming) has shown that patients are willing to pay a premium to visit mission health centers with one exception: child delivery at clinics and hospitals. Patients always pay the attending physician or nurse an 'appreciation' when the delivery is successful. A birth is one of the few medical 'interventions' whose result can be immediately assessed. The outcome is verifiable and it appears that side-payments do increase quality for this one service.

\section{Simulation of Possible Government Policies}

Though this paper takes a novel look at traditional healers we do not see them as the answer to the serious deficiencies in the provision of health care in rural Africa. The institution of traditional medicine invokes truth-telling in a way that modern providers can never replicate. Therefore contingent-payment contracts cannot be introduced in organizational health care. Furthermore attempts by the government to use traditional healers as their representatives are likely to break down the institution of traditional medicine, not extend it. However we study two institutions, not just one. The institution of traditional medicine was investigated to illuminate its contrasting institution, that of moderm 
medicine. In this section we look at various possible government policies to improve the quality and accessibility of health care and show that the government can make great strides by recognizing the value of the institution within which it must operate.

The population of the sub-division was listed in 1993 as 100,010 people. Our survey reached 4,484 people, or about $5 \%$ of the population. If we weight according to our sampling method we have interviewed randomly in villages representing 67,527 people, or $67 \%$ of the population. To create a sample representative of the sub-division, we weight the survey and then multiply by 1.5 . Thus we estimate that 11,817 people made first visits to one of the five providers we are studying.

We assume everyone in our sample acted rationally but 2 major sources of inefficiency remain. The first is that travel costs are transaction costs; they are paid by patients, but they are not recuperated by practitioners and they purchase no skill, drugs or effort. For travels to local clinics and hospitals this is a minor consideration, but for travels to mission hospitals this is a significant cost. A government policy which increases the probability of visits to local clinics and hospitals over mission hospitals will allow patients to save travel costs and will increase the net social benefit of health care.

The second source of inefficiency is the subject of this work, imperfect information in the supply of factor inputs. Were health care bought and sold on an open market we would expect the marginal benefit and cost of medical effort to be equal. Since the patient cannot purchase the marginal unit of health care, the inefficiency remains. If the government can increase the amount of effort supplied at anywhere near its opportunity cost the net benefit to society could be quite large.

We examine in this section a few simple policy measures and their predicted affect on the health and utility of the population of the sub-division.

\subsection{Base Run}

The empirical estimation produces a probability of a visit to any given provider. In a sample of 100 people identical to the interviewed individual the number who are likely to visit any particular provider is equal to the probability of a visit to that provider times 
100. Thus from the probabilities we can estimate the proportion of the sample who will visit any given provider.

\begin{tabular}{|c|c|c|c|c|c|c|}
\hline group & method & healer & gov clinic & gov hosp & mis clinic & mis hosp \\
\hline \multicolumn{7}{|c|}{ Total Visits } \\
\hline \multirow[t]{3}{*}{ All } & sample (predicted) & 86 & 144 & 117 & 134 & 54 \\
\hline & sample (observed) & 61 & 154 & 127 & 140 & 53 \\
\hline & population (predicted) & 1708 & 3129 & 2559 & 3192 & 1229 \\
\hline \multicolumn{7}{|c|}{ Percentage of Visits } \\
\hline \multirow[t]{3}{*}{ All } & sample (predicted) & 16 & 27 & 22 & 25 & 10 \\
\hline & sample (observed) & 11 & 29 & 24 & 26 & 10 \\
\hline & sub-division (predicted) & 14 & 26 & 22 & 27 & 10 \\
\hline \multirow[t]{3}{*}{ Poorest } & sample (predicted) & 17 & 27 & 22 & 24 & 10 \\
\hline & sample (observed) & 15 & 32 & 24 & 22 & 07 \\
\hline & sub-division (predicted) & 16 & 28 & 20 & 26 & 10 \\
\hline \multirow[t]{3}{*}{ Infants } & sample (predicted) & 16 & 28 & 21 & 25 & 10 \\
\hline & sample (observed) & 05 & 37 & 18 & 37 & 02 \\
\hline & sub-division (predicted) & 16 & 28 & 20 & 26 & 10 \\
\hline \multirow[t]{3}{*}{ Women } & sample (predicted) & 15 & 28 & 22 & 25 & 10 \\
\hline & sample (observed) & 13 & 29 & 24 & 24 & 10 \\
\hline & sub-division (predicted & 14 & 27 & 21 & 27 & 10 \\
\hline \multirow[t]{3}{*}{ Remote } & sample (predicted) & 19 & 25 & 22 & 24 & 10 \\
\hline & sample (observed) & 17 & 32 & 18 & 21 & 11 \\
\hline & sub-division (predicted) & 19 & 25 & 22 & 24 & 10 \\
\hline
\end{tabular}

Table 3 shows three different estimates of patterns of visits for five subgroups of the population. The groups include the entire population, women, infants (under 5 years of age), the poor (lowest quartile according to household wealth), and the most remote (upper quartile of distance to a organizational provider). We chose these groups because they represent populations that might be targeted by government policy. Shown in the table are the proportion of visits predicted by the model, the observed pattern of visits and the pattern for the whole population of the sub-division predicted by the model. The sample and sub-division estimates are different because the survey under-sampled residents of big villages who are more likely to have lower travel costs or have a government clinic or hospital present in the village itself.

The predictions follow the observed data relatively well, though the predictions for 
infants are disappointing. We re-ran the model including a dummy variable for infants in the calculation of the efficiency of the patient at transforming health inputs into health care. This improved the overall number of correct predictions (comparing the model to the sample) from $40 \%$ to $43 \%$ and improved the model's prediction of visits for children ${ }^{12}$. The results suggest that infants have a higher efficiency than other individuals and therefore visit government clinics more than other individuals because they are able to do more with the care they receive there. This could be because the illnesses from which they suffer are easier to cure with known treatments. Certainly medical evidence would suggest this, but it should have been captured in the characteristics of the disease reported. The result for infants suggests that our attempt to measure the characteristics of diseases is lacking, especially with respect to children. We choose to acknowledge the shortcomings of our data rather than include dummy variables that, though they help our predictions (though not the likelihood), circumvent the spirit of the model. The overall predictions are close enough to the observed patterns that we can justify the use of the model for policy analysis ${ }^{13}$.

The base run to which we compare the results of our policy simulations is the results for the population of the sub-division. The schema reported in Table 3 gives the total number of visits expected to any given provider by patients in Mbonge sub-division in a month.

\begin{tabular}{l||l|l|l|l|l}
\multicolumn{3}{c}{ Table 4: Base Run: Average Net Benefit per Individu } \\
subgroup & healer & gov clinic & gov hosp & mis clinic & mis hosp \\
\hline \hline All & 31.31 & 35.84 & 45.04 & 41.22 & 51.93 \\
Poorest & 4.94 & 5.96 & 5.32 & 5.71 & 3.81 \\
Infant & 4.33 & 7.62 & 6.61 & 7.33 & 4.63 \\
Women & 12.83 & 18.11 & 18.28 & 19.63 & 15.12 \\
Remote & 5.00 & 2.32 & 3.69 & 2.41 & 5.21
\end{tabular}

Table 4 shows the average utility or net benefit from health care ${ }^{14}$. The net benefit

\footnotetext{
${ }^{12} \mathrm{LR}$ ratio test of the restriction that the coefficient of the additional dummy variable is equal to zero fails to reject the null $(L R=1.46,1 \mathrm{df}, \mathrm{p}$-value $=0.22)$.

${ }^{13}$ Note, that since the model under-predicts visits to government clinics and the policies we examine attempt to improve government centers we will be under-estimating the benefit to children.

${ }^{14}$ Utility is not strictly aggregable across individuals because, though we know the value of health care
} 
represents the total utility from health care for an average individual. Thus the average visit to a mission hospital results in 52,000 CFA worth of increased earning potential (about 104 USD), despite higher drug costs, travel costs and fixed fees. Note that this is not the benefit to the average individual of visiting a mission hospital, but the benefit to the average individual who decides to visit a mission hospital.

\begin{tabular}{|c|c|c|c|c|c|}
\hline \multirow{3}{*}{\multicolumn{2}{|c|}{\begin{tabular}{l||l} 
subgroup & healer \\
Effort for the average visit
\end{tabular}}} & \multicolumn{3}{|c|}{ able 5: Base Run: Provider Efforts } & \multirow[b]{2}{*}{ mis hosp } \\
\hline & & gov clinic & gov hosp & mis clinic & \\
\hline & & 0.83 & 1.81 & 1.37 & 2.36 \\
\hline
\end{tabular}

Table 5 shows the average level of effort exerted by each practitioner. These figures can also be read in terms of 1,000 CFA. We look at effort in the base run because policies will change the amount of effort exerted, and this additional effort must be compensated. For traditional healers effort is compensated by the patient, but practitioners at government and mission clinics and hospitals must be compensated by their employer. For the policies we examine the only relevant change in effort (requiring compensation) is that of government centers.

\subsection{Price (Fees and Drug Cost) Based Policies}

Reducing fees collected or the cost of drugs, though often debated, is not a financially feasible policy for cash-strapped African governments. However there is a strong belief that, if it were possible, it would be one of the most effective ways to transfer resources to the rural poor and disadvantaged. We examine this policy here to show that it is not superior to other policies that are financially feasible.

\subsubsection{Reducing Fees at Government Centers}

The first policy which we examine is that of eliminating the fixed fees at government centers. Since the fees fall further at hospitals this increases the percentage of visits to

compared to observed expenditures, we do not know how these utilities relate across individuals. However aggregation is necessary for simplicity of exposition. 


\begin{tabular}{|c|c|c|c|c|c|}
\hline subgroup & $\begin{array}{l}\text { Table } 6 \\
\text { healer }\end{array}$ & $\begin{array}{l}\text { Reduced Fees a } \\
\text { gov clinic }\end{array}$ & $\begin{array}{l}\text { Governme } \\
\text { gov hosp }\end{array}$ & $\begin{array}{l}\text { Centers: } \\
\text { mis clinic }\end{array}$ & $\begin{array}{l}\text { attern of } \\
\text { mis hosp }\end{array}$ \\
\hline \multicolumn{6}{|c|}{ Change in percentage of total visits } \\
\hline All & -0.14 & -0.09 & 0.70 & -0.34 & -0.14 \\
\hline Poorest & -0.15 & -0.08 & 0.67 & -0.32 & -0.12 \\
\hline Infants & -0.14 & -0.09 & 0.69 & -0.33 & -0.13 \\
\hline Women & -0.14 & -0.09 & 0.69 & -0.34 & -0.13 \\
\hline Remote & -0.17 & -0.09 & 0.71 & -0.30 & -0.14 \\
\hline
\end{tabular}

government hospitals (see Table 6). The fees are a small portion of the total costs to patients (after drug costs and then travel costs) and therefore the total change in the pattern of visits is small.

\subsubsection{Reducing Drug Costs at Government Centers}

The government could also choose to reduce drug costs at government centers (both clinics and hospitals). This would have the largest affect at hospitals where the drugs are more expensive to begin with. Reducing drug costs by $50 \%$ causes visits to government hospitals to increase by $8 \%$. The change in the pattern of visits is similar across groups with the greatest benefit going to the remote (see Table 7).

Table 7: Reduce Drug Prices at Government Centers: Pattern of Visits

\begin{tabular}{l||l|l|l|l|l} 
subgroup & healer & gov clinic & gov hosp & mis clinic & mis hosp \\
\hline \hline \multicolumn{1}{l}{ Change in percentage of total visits } \\
All & -1.78 & 0.14 & 8.13 & -4.70 & -1.78 \\
Poorest & -2.02 & 0.24 & 7.55 & -4.36 & -1.41 \\
Infants & -1.50 & 0.25 & 6.00 & -3.47 & -1.27 \\
Women & -1.72 & 0.19 & 7.58 & -4.52 & -1.53 \\
Remote & -2.65 & 0.03 & 9.13 & -4.53 & -1.97
\end{tabular}

The major cost of such a policy is the cost of supplying drugs. If we assume that the price originally charged was equal to the cost then the government has to make up the difference in price for every unit sold. The average subsidy at a government clinic will be 2,225 CFA per visit and we predict 3,207 visits to government clinics with the new policy or a cost of $7,136,000$ CFA for clinics. The average subsidy for a visit to a government hospital is 5,981 CFA per visit and we predict 3,560 visits to hospitals at an expected cost 
of $21,292,000$ CFA. The total cost to subsidize drugs is $28,428,000$ CFA.

The change in utility per patient is recorded in Table 8 . The total benefit to the population of this policy is $29,497,000 \mathrm{CFA}$.

Table 8: Halve Drug Prices at Government Centers: Utility

\begin{tabular}{|c|c|c|c|c|c|c|c|}
\hline subgroup & change & healer & gov clinic & gov hosp & mis clinic & mis hosp & total \\
\hline All & $\begin{array}{l}\text { Total } \\
\text { Average }\end{array}$ & -6509 & 5874 & 69254 & -27376 & -11745 & $\begin{array}{l}29497 \\
2.50\end{array}$ \\
\hline Poorest & $\begin{array}{l}\text { Total } \\
\text { Average }\end{array}$ & -981 & 1437 & 9270 & -3394 & -930 & $\begin{array}{l}5402 \\
2.24\end{array}$ \\
\hline Infants & $\begin{array}{l}\text { Total } \\
\text { Average }\end{array}$ & -514 & 1629 & 8820 & -3175 & -771 & $\begin{array}{l}5990 \\
1.74\end{array}$ \\
\hline Women & $\begin{array}{l}\text { Total } \\
\text { Average }\end{array}$ & -2514 & 3244 & 28486 & -12055 & -3839 & $\begin{array}{l}13323 \\
2.24\end{array}$ \\
\hline Remote & $\begin{array}{l}\text { Total } \\
\text { Average }\end{array}$ & -987 & 411 & 6004 & -1693 & -1329 & $\begin{array}{l}2407 \\
2.85\end{array}$ \\
\hline
\end{tabular}

The extra effort exerted by practitioners at government hospitals is large because they are seeing so many extra patients. The compensation required is on the order of $1,900,000$ CFA (see Table 9).

Table 9: Halve Drug Prices at Government Centers: Effort

\begin{tabular}{l||l|l|l|l|l|l} 
& healer & gov clinic & gov hosp & mis clinic & mis hosp & total \\
\hline \hline Change in Effort & -954 & -13 & 1913 & -880 & -596 & \\
Relevant to government & & -13 & 1913 & & & 1900
\end{tabular}

The costs of the policy are conservatively estimated at 30 million CFA and the benefits are estimated at 30 million, or a cost benefit ratio of approximately 1:1. This is not necessarily a bad ratio if the goal is to transfer resources to vulnerable populations, but it must be compared to the benefit cost ratio of other possible policies. The investigation of this policy alternative does not take into account the difficulty of ensuring consistent supply of a subsidized good, especially in the rural areas. If history is a guide, decreasing the cost will decrease the supply in clinics and most hospitals. 


\subsection{Quality (Incentive) Based Policies}

Reducing costs at government health centers can reduce transaction costs by reducing the amount of time spent traveling. However the responsiveness of patient demand to reduced costs is low, because costs are being reduced at low quality centers, and cost and quality are poor substitutes. Quality at hospitals is higher, but government hospitals have much higher travel costs than clinics. To recapture the potential benefit lost to transaction costs the government would have to address the gap between the benefit to health care of provider effort and the cost of providing that effort.

In this section we examine the benefit of improving quality through the instrument of this investigation, the penalty for providing sub-standard services.

\subsubsection{Increasing Government Penalty in Case of sub-standard performance}

We consider a policy that changes the way health care is delivered at government centers, an increase in the penalty at government centers by $40 \%$. This would bring the expected penalty closer to that of mission centers by $75 \%$. We assume that the cost of this policy is the increased salary necessary to compensate government employees for the extra effort they are required to exert. In this area of Cameroun the government is already gathering the information required to assess quality.

Table 10: Increase Penalty at Government Centers: Pattern of Visits

\begin{tabular}{l||l|l|l|l|l} 
subgroup & healer & gov clinic & gov hosp & mis clinic & mis hos \\
\hline \hline \multicolumn{1}{l}{ Percentage of total visits } \\
All & -0.68 & 2.58 & 0.91 & -1.86 & -0.96 \\
Poorest & -0.61 & 2.08 & 0.50 & -1.37 & -0.60 \\
Infants & -0.38 & 1.50 & 0.19 & -0.94 & -0.37 \\
Women & -0.64 & 2.41 & 0.61 & -1.67 & -0.70 \\
Remote & -1.35 & 2.84 & 1.51 & -1.84 & -1.16
\end{tabular}

The pattern of visits changes the most for government clinics and it appears they are drawing most of their clients from mission clinics (see Table 10). There are more government clinics than mission clinics so this policy is similar to reducing the travel cost to higher quality clinics. 
Table 11: Increase Penalty at Government Centers: Utility

\begin{tabular}{|c|c|c|c|c|c|c|c|}
\hline subgroup & change & healer & gov clinic & gov hosp & mis clinic & mis hosp & total \\
\hline All & $\begin{array}{l}\text { Total } \\
\text { Average }\end{array}$ & -3985 & 22288 & 17202 & -12811 & -11198 & $\begin{array}{l}11496 \\
0.97\end{array}$ \\
\hline Poorest & $\begin{array}{l}\text { Total } \\
\text { Average }\end{array}$ & -480 & 2845 & 1325 & -1240 & -653 & $\begin{array}{l}1796 \\
0.75\end{array}$ \\
\hline Infants & $\begin{array}{l}\text { Total } \\
\text { Average }\end{array}$ & -119 & 2295 & 566 & -845 & -214 & $\begin{array}{l}1681 \\
0.49\end{array}$ \\
\hline Women & $\begin{array}{l}\text { Total } \\
\text { Average }\end{array}$ & -1634 & 9911 & 4302 & -5319 & -2250 & $\begin{array}{l}5009 \\
0.84\end{array}$ \\
\hline Remote & $\begin{array}{l}\text { Total } \\
\text { Average }\end{array}$ & -953 & 1662 & 2287 & -783 & -1247 & $\begin{array}{l}965 \\
1.14\end{array}$ \\
\hline
\end{tabular}

The utility of the patient increases and the remote benefiting the most (see Table 11). The total increase in benefit to the sub-division is $11,496,000$ CFA.

Table 12: Increase Penalty at Government Centers: Effort

\begin{tabular}{l||l|l|l|l|l|l} 
subgroup & healer & gov clinic & gov hosp & mis clinic & mis hosp & total \\
\hline \hline Change in Effort & -913 & 1465 & 1188 & -377 & -342 & 1022 \\
Relevant to government & & 1465 & 1188 & & & 2653
\end{tabular}

Increasing the penalty clearly increases the amount of effort that practitioners at government clinics and hospitals must provide. This increased effort must be compensated. Table 12 shows an estimated compensation required of 2,653,000 CFA.

The costs of this policy are estimated to be on the order of 2.6 million CFA and the benefits on the order of 11 million CFA, a cost benefit ratio of approximately 1:4. This is clearly superior, even for vulnerable populations, than policies that subsidize costs without addressing quality.

\subsubsection{Increasing incentives and fees}

It is not necessary that the government incur any expenses in its efforts to increase quality. Many studies have shown that patients are willing to pay more for better quality. This paper explicitly addresses the odd fact that, in a country where side-payments are common, patients cannot unilaterally pay for better quality. When there is imperfect information and unverifiable outcomes institutions must insure quality before patients will be willing 
to pay. The policy we examine makes the role of institutions in increasing quality explicit. The government must enforce the standards that it already has in place.

We examine here a policy in which the fees at clinics rise to 300 CFA (from 100 CFA) and the cost of hospitals rise to 1200 CFA (from $600 \mathrm{CFA}$ ). The penalty (or frequency of monitoring) rises by $40 \%$ in both centers.

Table 13: Increase penalty and fees at government centers: Pattern of Visits \begin{tabular}{l||l|l|l|l|l} 
subgroup & healer & gov clinic & gov hosp & mis clinic & mis hosp \\
\hline
\end{tabular}

\begin{tabular}{l||c|c|c|c|c}
\hline \multicolumn{3}{l|}{ Percentage of total visits } \\
All & -0.53 & 2.48 & 0.43 & -1.55 & -0.83 \\
Poorest & -0.45 & 1.98 & 0.04 & -1.07 & -0.49 \\
Infants & -0.21 & 1.38 & -0.27 & -0.64 & -0.26 \\
Women & -0.49 & 2.30 & 0.14 & -1.36 & -0.58 \\
Remote & -1.17 & 2.76 & 1.02 & -1.57 & -1.04
\end{tabular}

This policy increases the number of visits to government clinics and hospitals (see Table 13). Again the most remote exhibit the greatest change in the pattern of visits.

Table 14: Increase penalty and fees at Government Centers: Utility

\begin{tabular}{|c|c|c|c|c|c|c|c|}
\hline subgroup & change & healer & gov clinic & gov hosp & mis clinic & mis hosp & total \\
\hline All & $\begin{array}{l}\text { Total } \\
\text { Average }\end{array}$ & -3566 & 21371 & 13895 & -11452 & -10603 & $\begin{array}{l}9645 \\
0.82\end{array}$ \\
\hline Poorest & $\begin{array}{l}\text { Total } \\
\text { Average }\end{array}$ & -417 & 2658 & 842 & -1051 & -596 & $\begin{array}{l}1436 \\
0.60\end{array}$ \\
\hline Infants & $\begin{array}{l}\text { Total } \\
\text { Average }\end{array}$ & -84 & 2054 & 51 & -655 & -181 & $\begin{array}{l}1186 \\
0.35\end{array}$ \\
\hline Women & $\begin{array}{l}\text { Total } \\
\text { Average }\end{array}$ & -1422 & 9414 & 2824 & -4659 & -2053 & $\begin{array}{l}4103 \\
0.69\end{array}$ \\
\hline Remote & $\begin{array}{l}\text { Total } \\
\text { Average }\end{array}$ & -891 & 1601 & 2018 & -703 & -1198 & $\begin{array}{l}827 \\
0.98\end{array}$ \\
\hline
\end{tabular}

The utilities are recorded in Table 14. Again the most remote benefit the most on average, but it is important to note that every vulnerable group benefits from this policy despite the increased fees. The total benefit to the sub-division is $9,645,000$ CFA.

The increase in the effort of practitioners is slightly smaller than in the simulation where penalties were raised without increasing fees because the response of patients is less when the fees are higher. 
Table 15: Increase Penalty and fees at Government Centers: Effort

\begin{tabular}{l||l|l|l|l|l|l} 
subgroup & healer & gov clinic & gov hosp & mis clinic & mis hosp & total \\
\hline \hline Total change & -835 & 1454 & 1069 & -325 & -306 & 1057 \\
Relevant to government & & 1454 & 1069 & & & 2523
\end{tabular}

The costs of this policy is the increased compensation required by practitioners but now these costs can be met by the increased fees We deliberately created this policy so that the increase in fees would approximately compensate the practitioners ${ }^{15}$. Without any new government expenditures this policy benefits the entire population including the four vulnerable groups.

This particular policy is important in the debate over decentralization. Increased fees are collected at centers according to the increase in quality at that center. This policy does not require that the fees be centrally collected and then paid out again to the centers. The fees can remain in the center where they would compensate the practitioners at that center. However, there is a very important role for the government: the penalty must be enforced. The institution is the difference between centers requiring side-payments but not producing better quality, and centers collecting higher fees and selling quality health care.

\section{Conclusion}

Imperfect information in the supply of inputs introduces transaction costs to the market for health care. In Cameroun two basic forms of institution have arisen to solve these problems. Traditional healers have low levels of skill but operate within an institution that allows them to operate on a contingent-payment contract basis. This allows them to provide health care to a niche of the market that is able to substitute skill for high levels of effort. Organizational providers, on the other hand, operate in an environment in which the

\footnotetext{
${ }^{15}$ Originally clinics received 3,129 visits and would therefore collect 626,000 CFA in additional fees from these visitors as well as 293 new visits earning 300 CFA each $(88,000$ CFA). Originally hospitals received 2,559 visits and would now collect an additional 600 CFA from each or 1,535,000 CFA. They also receive 51 additional visits earning 1,200 CFA each $(61,000 \mathrm{CFA})$. The total in new fees collected is therefore approximately $2,310,000$ CFA.
} 
budget of value created by health care can be broken, allowing them to achieve potentially superior solutions. We argue that, mission organizations take greater advantage of the opportunities created by budget-breaking than do government organizations. By explicitly defining the role of institutions in the market for imperfectly supplied inputs we show how changes in government policy can reduce the transaction cost associated with seeking quality health care.

We have fit a relatively simple model to data collected in Cameroun. We show that patients choose practitioners in part because the demand for unobservable inputs resulting from the conditions under which they suffer leads them to the contract that appropriately supplies those inputs. This is precisely what patients say in focus group interviews; their choice of provider depends on what disease they think they have. The model fits well and produces results that are in line with our prior expectations. Similarly our policy recommendations parallel the collected wisdom in the field. It is impossible to show that any structural estimation is econometrically superior to all other possible structural forms. Rather, we show that, with a few important theoretical assumptions, we can reproduce the observed choices of patients, the payments to traditional healers and the compensations practitioners expect within the confines of a rigorous framework. 


\section{References}

Arrow, Kenneth J., "Uncertainty and the Welfare Economics of Medical Care," American Economic Review, 1963, 53, 941-973.

- , "The Economics of Agency," in J. Pratt and R. Zeckhauser, eds., Principals and Agents, Cambidge, MA: Harvard Business School, 1985.

Baerts, Martine, Guerisseurs et plantes medicinales de la region des cretes Zaire-Nil au Burundi number 18. In 'Annales Science Economiques.', Tervuren, Belgie: Koninklijk Museum voor Midden-Afrika, 1989.

Conco, W. Z., "The African Bantu practice of medicine: Some preliminary observations," Social Science and Medicine, 1972, 6 (3), 283-322.

Dranove, David and William D. White, "Agency and the Organization of Health Care Delivery," Inquiry, 1987, 24, 405-415.

Edwards, S.D, Indigenous African healers and western trained psychologists: a comparative study of interview methods number 38. In 'Publication series of University of Zululand, series B.', Kwa Dlangezwa, South Africa: University of Zululand, 1983.

Eswaran, Mukeshi and Ashok Kotwal, "A Theory of Contractual Structure in Agriculture," American Economic Review, 1985, 75, 352-367.

Gelfand, M., S. Mari, R.D. Drummond, and B. Ndemera, The Traditional Medical Practitioner in Zimbabwe: His principles of practice and pharmacopoeia, Harare, Zimbabwe: Mambo Press, 1985.

Grossman, Michael, "On the Concept of Health Capital and the Demand for Health," Journal of Political Economy, 1975, 80, 223-255.

Hart, Oliver and Bengt Holmstrom, "The Theory of Contracts," in Truman F. Bewley, ed., Advances in Economic Theory: Fifth World Congress, number 12. In 'Econometric Society monographs.', Cambidge: Cambridge University Press, 1987.

Holmstrom, Bengt, "Moral Hazard in Teams," Bell Journal of Economics, 1982.

Korse, Piet et al., Sorcellerie, maladie et chasseur de sorciers chez les Mongo (Rep. du Zaire) number 103. In 'CEEBA, series 11.', Bandundu, Zaire: Publications (CEEBA), 1989.

Lasker, Judith N., "Choosing among therapies: illness behavior in the Ivory Coast," Social Science and Medicine, 1981, 15 A (2), 157-68.

Leonard, Kenneth L., "Contractual Structure of Health Care in Rural Cameroun." PhD dissertation, University of California at Berkeley May 1997.

- , "African Traditional Healers: Incentives and Skills in Health Care Delivery," Discussion Paper Series 9798-13, Columbia University 1998.

Ndeso-Atanga, Sylvester, "Health Care Quality and the Choice of Care Providers in Rural Cameroon," in David K. Leonard, ed., Africa's Changing Markets for Human and Animal Health Services, MacMillan Publishers, forthcoming.

North, Douglass C., Institutions, Insituttional Change and Economic Performance, Cambridge: Cambridge University Press, 1990.

Oyenye, O.Y. and I.O. Orubuloye, Some aspects of Traditional Medicine in Bendel State of Nigeria: An exploratory study number 14. In 'Niser monograph series.', Ibadan, Nigeria: Nigerian Institute of Social and Economics Research, 1985. 
Staugård, Frants, Traditional Medicine in Botswana, Vol. 1, Gaborone, Botswana: Ipelegeng Publishers, 1985. 


\section{A Proof of proposition 2}

We simplify $\omega_{i} \mu$ to $\mu$ without loss of generality for simplicity of exposition. The lagrangian is formed as follows;

$$
L=\mu-d-c+\lambda_{1}\left(r \frac{\partial}{\partial a} \mu-\frac{d}{d a} c\right)+\lambda_{2}\left((1-r) \frac{\partial}{\partial b} \mu-\frac{d}{d b} d\right)
$$

Using the envelope condition we solve for the change in utility with respect to a change in the sharing rule.

$$
\frac{\partial L}{\partial r}=\lambda_{1} \frac{\partial}{\partial a} \mu-\lambda_{2} \frac{\partial}{\partial b} \mu
$$

differentiating the lagrangian with respect to $a$ and $b$ we solve for the two multipliers.

$$
\lambda_{1}=-\frac{\frac{\partial}{\partial a} \mu-\frac{d}{d a} c+\lambda_{2} \frac{\partial^{2}}{\partial a \partial b} \mu-\lambda_{2}\left(\frac{\partial^{2}}{\partial a \partial b} \mu\right) r}{r \frac{\partial^{2}}{\partial a^{2}} \mu-\frac{d^{2}}{d a^{2}} c}
$$

which then leads to an expression of $\lambda_{2}$.

$$
\lambda_{2}=-\frac{\left(\frac{\partial}{\partial b} \mu-\frac{d}{d b} d-\frac{r\left(\frac{\partial^{2}}{\partial a \partial b} \mu\right) \frac{\partial}{\partial a} \mu}{r \frac{\partial^{2}}{\partial a^{2}} \mu-\frac{d^{2}}{d a^{2}} c}+\frac{r\left(\frac{\partial^{2}}{\partial a b b} \mu\right) \frac{d}{d a} c}{r \frac{\partial^{2}}{\partial a^{2}} \mu-\frac{d^{2}}{d a^{2}} c}\right)}{\left(-\frac{r\left(\frac{\partial^{2}}{\partial a \partial b} \mu\right)^{2}}{r \frac{\partial^{2}}{\partial a^{2}} \mu-\frac{d^{2}}{d a^{2}} c}+\frac{r^{2}\left(\frac{\partial^{2}}{\partial a \partial b} \mu\right)^{2}}{r \frac{\partial^{2}}{\partial a^{2}} \mu-\frac{d^{2}}{d a^{2}} c}+\frac{\partial^{2}}{\partial b^{2}} \mu-\left(\frac{\partial^{2}}{\partial b^{2}} \mu\right) r-\frac{d^{2}}{d b^{2}} d\right)}
$$

Note that

$$
\frac{\partial}{\partial b} \mu-\frac{d}{d b} d=e \frac{\partial}{\partial b} \mu
$$

and it should be clear that $\lim _{r \rightarrow 0} \lambda_{2}=0$. This makes sense since all of the incentives to provide effort lie with the patient when the sharing rule is equal to zero the cost of the incentive compatibility constraint is smaller and smaller. However $\lambda_{1}$ does not go to zero as $r$ goes to zero.

$$
\lim _{r \rightarrow 0} \lambda_{1}=(1-r) \frac{\frac{\partial}{\partial a} \mu}{\frac{d^{2}}{d a^{2}} c}
$$

Substituting both multipliers into the envelope condition we find

$$
\lim _{r \rightarrow 0} \frac{\partial}{\partial r} L=\frac{\left(\frac{\partial}{\partial a} \mu\right)^{2}}{\frac{d^{2}}{d a^{2}} c}
$$

This condition is positive given that there are increasing marginal costs to effort. Note that the system is not solvable if this is not the case. Thus as $r$ approaches zero there is 
a benefit to increasing $r$. Note that this does not rely on any assumptions about the sign of the cross partial of output with respect to $a$ and $b$.

\section{B Simulated Normal Distribution}

The conditional probit with simulated normal is solved by adding to each expected utility 1,000 normally distributed errors and taking as the probability, the number of times the expected utility of a choice is greater than all others, divided by 1,000. The maximum likelihood is found by a simplex algorithm.

Table 16 shows the coefficient of the conditional probit, the coefficient of the conditional logit, the standard error of the conditional logit and the number of standard deviations between the two estimated sets of coefficients.

\begin{tabular}{|c|c|c|c|c|}
\hline $\begin{array}{l}\log \text { likelihood }-789.64 \\
\text { variable }\end{array}$ & coefficient & logit coeff & std err & deviations \\
\hline$\overline{\mathrm{B}_{1} \text { standard error }}$ & 19.43 & 11.61 & 1.338 & $\overline{5.84}$ \\
\hline $\mathrm{B}_{2}$ responsiveness factor & 0.503 & 0.550 & 0.1111 & 0.43 \\
\hline$B_{3}$ skill exponent & 1.01 & 0.647 & 0.4989 & 0.73 \\
\hline$K_{\text {mission }}$ (mission penalty basis) & 0.660 & 0.5434 & 0.2661 & 0.44 \\
\hline$K_{\text {hospital }}$ (hospital penalty basis) & 1.155 & 1.079 & 0.4984 & 0.15 \\
\hline$H_{0}$ & -10.36 & -8.095 & 2.279 & 0.99 \\
\hline$H_{1}\left(\gamma_{k}\right)$ & 0.788 & 0.695 & 0.2303 & 0.40 \\
\hline$H_{2}\left(\sigma_{k}\right)$ & 2.245 & 1.707 & 0.5523 & 0.97 \\
\hline$H_{3}\left(\gamma_{k} \cdot \sigma_{k}\right)$ & -0.248 & -0.184 & 0.07 & 0.91 \\
\hline$H_{4}\left(\pi_{h, k}\right)$ & 0.200 & 0.118 & 0.1202 & 0.68 \\
\hline $\mathrm{E}_{0}$ constant & 6.200 & 5.695 & 4.517 & 0.11 \\
\hline$E_{1}$ family wealth (ln) & 1.129 & 1.133 & 0.7817 & 0.01 \\
\hline $\mathrm{E}_{2}$ age & 0.390 & 0.4395 & 0.161 & 0.30 \\
\hline $\mathrm{E}_{3}$ age $^{2}$ & -0.0032 & -0.0042 & 0.0019 & 0.53 \\
\hline $\mathrm{E}_{4}$ gender $($ female $=1)$ & -0.723 & -0.935 & 1.482 & 0.14 \\
\hline$E_{5}$ student & -6.76 & -5.885 & 2.127 & 0.41 \\
\hline $\mathrm{E}_{6}$ farmer & -5.68 & -5.206 & 2.073 & 0.23 \\
\hline$E_{7}$ businessman or civil servant & 5.72 & 6.276 & 3.549 & 0.16 \\
\hline $\mathrm{E}_{8}$ age & -0.130 & -0.1312 & 0.057 & 0.02 \\
\hline$E_{9}$ gender $($ female $=1)$ & -3.567 & -3.542 & 1.678 & 0.01 \\
\hline $\mathrm{E}_{10}$ education & -0.475 & -0.4808 & 0.2283 & 0.03 \\
\hline$W_{0}$ (constant) & 41.866 & 41.73 & 12.34 & 0.01 \\
\hline$W_{1}$ (reported wage) & .0562 & 0.7041 & 0.5447 & 0.26 \\
\hline$W_{2}$ (family income for non-workers) & 0.299 & 0.4232 & 0.8224 & 0.15 \\
\hline
\end{tabular}




\title{
1997-1998 Discussion Paper Series
}

\author{
Department of Economics \\ Columbia University \\ 1022 International Affairs Bldg. \\ 420 West 118 th Street \\ New York, N.Y., 10027
}

The following papers are published in the 1997-98 Columbia University Discussion Paper series which runs from early November to October 31 of the following year (Academic Year).

The following is a website address where viewers may download some discussion papers. It is a project that is in progress, and therefore the site may not contain all recent working papers.

http://www.columbia.edu/dlc/wp/econ/index.html.

\section{For Ordering Hardcopies:}

Domestic orders for discussion papers are available for purchase at the cost of $\$ 8.00$ (U.S.) per paper and $\$ 140.00$ (US) for the series.

Foreign orders cost $\$ 10.00$ (US) per paper and $\$ 185.00$ for the series.

To order discussion papers, please write to the Discussion Paper Coordinator at the above address along with a check for the appropriate amount, made payable to Department of Economics, Columbia University. Please be sure to include the series number of the requested paper when you place an order. 
1997-98 Discussion Papers

Economics Department, Columbia University

\begin{tabular}{|c|c|c|}
\hline Seriestino. & (1) & A Authors \\
\hline $9798-01$ & Optimal Regulatory Transparency & Herk, L.F. \\
\hline $9798-02$ & Russia's Market Transition: Who Has Lost and How? & $\begin{array}{l}\text { Desai, } \mathrm{P} \text {. } \\
\text { Idson, T. }\end{array}$ \\
\hline $9798-03$ & The Wage Arrears Crisis in Russia & $\begin{array}{l}\text { Desai, } \mathrm{P} . \\
\text { Idson, } \mathrm{T} \text {. }\end{array}$ \\
\hline $9798-04$ & Taxes Versus Legal Rules as Instruments for Equity & Sanchirico, C.W. \\
\hline $9798-05$ & $\begin{array}{l}\text { Enforcement by Hearing: An Integrated Model of Evidence Production } \\
\text { draft: } 12 / 95 \text { ) }\end{array}$ & Sanchirico, C.W. \\
\hline 9798-06 & $\begin{array}{l}\text { Evidence Production, Adversarial Process and the Private Instigation of Suits } \\
\text { (first draft: } 12 / 95 \text { ) }\end{array}$ & Sanchirico, C.W. \\
\hline $9798-07$ & Structural VAR, MARMA and Open Economy Models & $\begin{array}{l}\text { Dhrymes, P.J. } \\
\text { Thomakos, D. }\end{array}$ \\
\hline 9798-08 & $\begin{array}{l}\text { Small Sample Properties of Certain Cointegration Test Statistics: A Monte Carlo } \\
\text { Study (Revd. from 7/96) }\end{array}$ & $\begin{array}{l}\text { Dhrymes, P.J. } \\
\text { Thomakos, D. }\end{array}$ \\
\hline $9798-09$ & $\begin{array}{l}\text { How More Taxes Can Be Better Than Less: A Note On Aggregating Deadweight } \\
\text { Losses }\end{array}$ & Lancaster, $\mathrm{K}$. \\
\hline $9798-10$ & $\begin{array}{l}\text { Environmental Self-Auditing: Setting the Proper Incentives for Discovering and } \\
\text { Correcting Environmental Harm }\end{array}$ & $\begin{array}{l}\text { Pfaff, A.S.P. } \\
\text { Sanchirico, C.W. }\end{array}$ \\
\hline $9798-11$ & Minimal Inclusive Sets in Special Classes of Games & Sanchirico, C.W. \\
\hline $9798-12$ & On the Sources of the Inflationary Bias & Piga, G. \\
\hline $9798-13$ & African Traditional Healers: Incentives and Skills in Health Care Delivery & Leonard, K.L. \\
\hline$\overline{9798-14}$ & Monotone Matching in Perfect and Imperfect Worlds & $\begin{array}{l}\text { Legros, P. } \\
\text { Newman, A.F. }\end{array}$ \\
\hline $9798-15$ & Tying and Innovation: A Dynamic Analysis of Tying Arrangements & Choi, J. P. \\
\hline $9798-16$ & $\begin{array}{l}\text { Institutional Structure of Health Care in Rural Cameroun: Structural Estimation of } \\
\text { Production in Teams with Unobservable Effort }\end{array}$ & Leonard, K.L. \\
\hline
\end{tabular}

